\title{
Waste Sorting Dustbin with Arduino based Smart Motor Rotating Tray
}

\author{
Josephine Doriya J , Krithika B , Divyanshi Agarwal, Mahesh Kumar
}

\begin{abstract}
Due to continuous growth in technology and industrialization there is rapid increase in the type and the volume of waste being generated. People throw garbage without realizing that it is affecting their own health and will degrade the future generation's living standards. In India, majority of waste is being disposed in a very unsatisfactory manner. Ensuring efficient waste management is becoming a threat for the government. For a developing country like INDIA, upgrading the current method of waste disposal is of utmost importance. One of the undeniable fact is that, if we continue to dump land sites at the current rate it may lead to severe environmental hazards. This may not only have an impact on environment, but also on the health of the society. This paper proposes a system in which waste is segregated at a basic level itself. This is achieved by using sensors for different types of waste. Once waste is been detected it has to be dropped into the slot allotted for it. This is done by dividing the bin into different slots using PVC solid sheet. A motor wing action is employed to drop the waste into appropriate slot.
\end{abstract}

Keywords: segregator, motor-wing action, sensors.

\section{INTRODUCTION}

In this modern era where development of smart cities is given utmost importance, there is a need for concentrating on waste segregation. Proper segregation of waste is necessary for proper disposal. In India 80 percent of waste is being disposed in a very unsatisfactory manner. There are lots of measures put by the government for waste segregation. Separate bins are being placed for each type of waste. But this is not effective due to negligence of people in this busy world.

Landfills are an increasingly pressing problem. Less and less land is available to deposit refuse, but the volume of waste is growing. As a result, segregating waste is not just of environmental importance, but also of economic concern. Segregation of waste at source is important. It's an effort that pays everybody and solves half the city's problem of waste management. Waste, if not segregated, can pose risks and constraints on the choice of operation of waste processing technologies. Plastic in waste if incinerated could lead to release of dioxins that are toxic. Household hazardous waste if not segregated (e.g. spent batteries) can result in compost that is contaminated. Segregated waste reduces health and safety related risks to waste pickers and to the ecosystems around the waste treatment and disposal sites.

Revised Manuscript Received on March 5, 2020.

Josephine Doriya J , School of EEE , REVA University ,Bengaluru, India

Krithika B , School of EEE , REVA University ,Bengaluru, India Divyanshi Agarwal, School of EEE, REVA University ,Bengaluru, India

Mahesh Kumar, School of EEE, REVA University ,Bengaluru, India maheshkumar@gmail.com
Today, the percentage of waste segregation in Asian cities is rather low. It hovers between $30 \%$ and $60 \%$. Segregation at source is however much higher in Japan, EU and Northern America, where it ranges between $60 \%$ and $90 \%$. Some cities have progressed on waste segregation by raising awareness, offering incentives and by imposing penalties or through enforcement. In order to 'localize' the benefits of waste segregation, technology is brought in for the rescue. The segregated waste like plastic and paper has been a valuable commodity sellable to local and foreign markets. Waste segregation helps in recycling and reprocessing of the waste and reduces the further consumption of natural resources.

Reasons due to which waste segregation is not effective:

(a) Lack of knowledge on waste disposal.

(b)Improper schedule of waste collection

\section{PROPOSED WORK}

Waste disposal is a major crisis in a developing country like India. The garbage from households collected is most of the time not segregated due to which the disposal becomes too much complicated. Most of the time waste is been treated by incineration. Though incineration of municipal waste coupled with energy recovery can form an essential part of integrated waste management system, yet strict controls are required to prevent its negative impact on human health and environment. Hence utmost importance must be given to segregation of waste at basic level itself.

We have designed a smart waste segregator which automatically segregates different types of waste like plastic, metal and wet waste [1]. For this purpose, we are using different types of sensors like moisture sensor, inductive sensor and capacitive sensor [7] for waste such as wet waste, metal waste and plastic waste respectively. This design can also detect the level up to which the bin is filled [3]. The level up to which the bin is filled is detected using the ultrasonic sensor. Based on the input given by this sensor, the motor rotates accordingly [2].

The waste segregator bin is divided into 4 divisions. The number of divisions in the bin depends on the number of waste which is to be segregated. Three wings are designed for dropping the waste into the bin. In which there is a main wing and two sub wings. Each sub wing is placed at $45^{\circ}$ to the main wing. Based on the type of waste, the rotation of bin is designed. The sensor circuit which detects the type of waste is fitted on top surface of the bin. Once a person places the waste on the door of the bin, the sensors detect the type of waste and the door of the bin opens and the waste falls on the wing which then drops into the division allotted for the waste. There is a door 
opening mechanism placed on the lid of the bin.

This has a servo motor connected beneath it, for opening and closing of the door[3][7]. Ultrasonic sensor which placed to detect whether waste is dropped into the bin. Once this detects an object an signal is been sent through arduino to open the door and close the same.

\section{DESIGN}

\section{A. Block diagram}

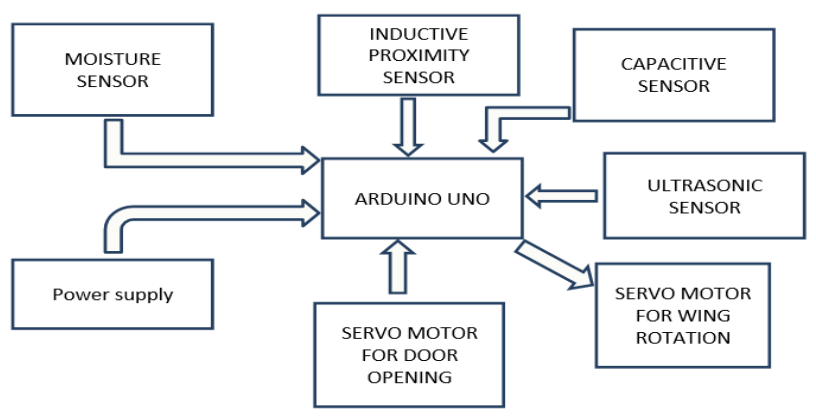

Fig. 1. Block Diagram

In this paper, separation of different types of waste is carried out using sensor and motor based operation[7]. The circuit is built such that all the sensors and motors are connected to arduino uno (microcontroller). Three sensors are used for detection of different type of waste. Moisture sensor is used to detect wet waste. Inductive proximity sensor is used for detecting metal waste i.e ferrous material etc. Capacitive proximity sensor is used for detecting nonmetallic waste such as wood, paper, plastic[1] etc. Ultrasonic sensor is used for two purposes in this project[7]. One is to detect whether any waste is dropped into the bin, which would initiate a signal from arduino microcontroller to servo motor used for door opening mechanism. Hence the waste would fall into the bin. Another purpose is to check how much the bin is filled. LED is used to indicate whether the system is ready.

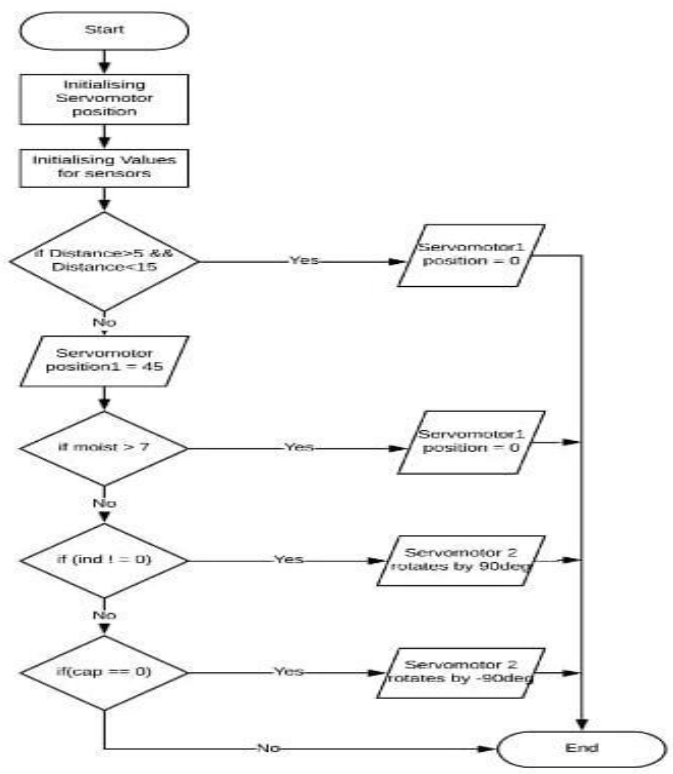

Fig: Flowchart of the process

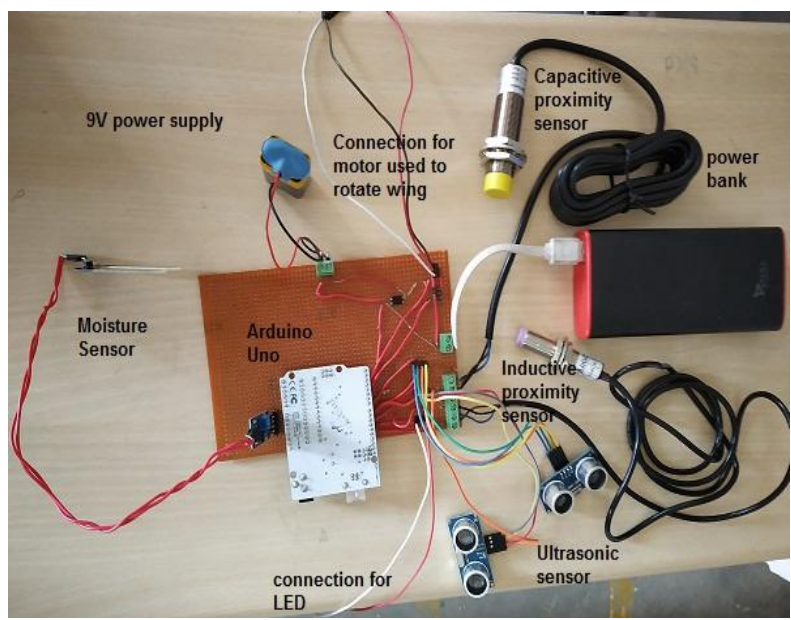

Fig. 2. Circuit Diagram

Door opening mechanism is used for opening and closing of the lid which is placed in the head in the bin. This is achieved by making use of servo motor MicroServo DXW90 9g[3]. Once a waste is dropped it is been detected by the ultrasonic sensor which is connected to arduino. This serves as an input to the servo motor mentioned above which rotates in the respective direction so as to open and close the lid.

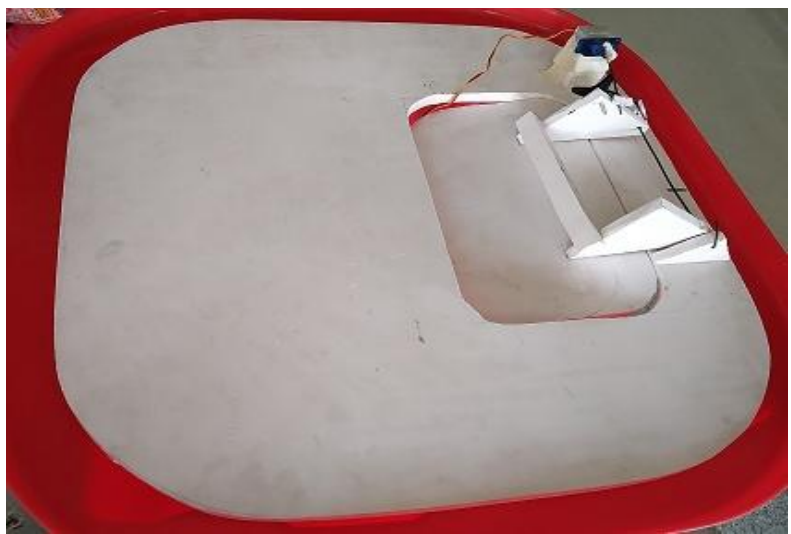

Fig. 3. Door Opening Mechanism

PVC solid sheet is used for separating the bin into different parts, wherein each part is used dedicated for each type of waste. These sheets are placed along the diagonal of the bin such that the bin gets divided into four. Servo motor [3] is placed at the intersection of the sheet by making a slot for it to fit in.

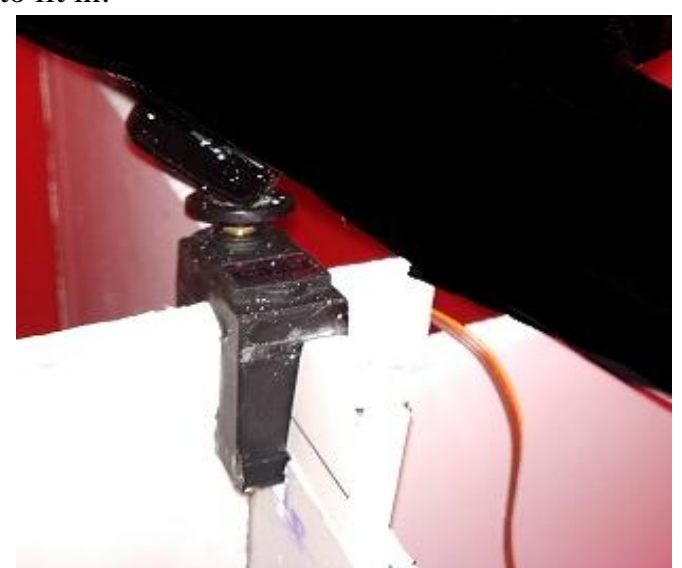

Fig. 4. Motor Screwed to Wing

Published By: 
A wing like structure made out of PVC pipe in which a pipe is laid out straight and two pipes are placed at $45^{\circ}$ with the former. A hole is drilled into the pipe, aligned at $45^{\circ}$, at the center of the straight pipe while placing $\mathrm{m}$-seal below it. This wing is screwed to the servomotor and placed in the intersection of solid sheet. Once wet waste is detected the wing remains in the same position. When metal waste is detected the wing rotates $90^{\circ}$ and the waste falls into the part allotted for metallic waste. Similarly, when paper or plastic waste is detected the wing rotates by $-90^{\circ}$ and is dropped into the slot allocated for it. Detection of type of waste is done by sensors.

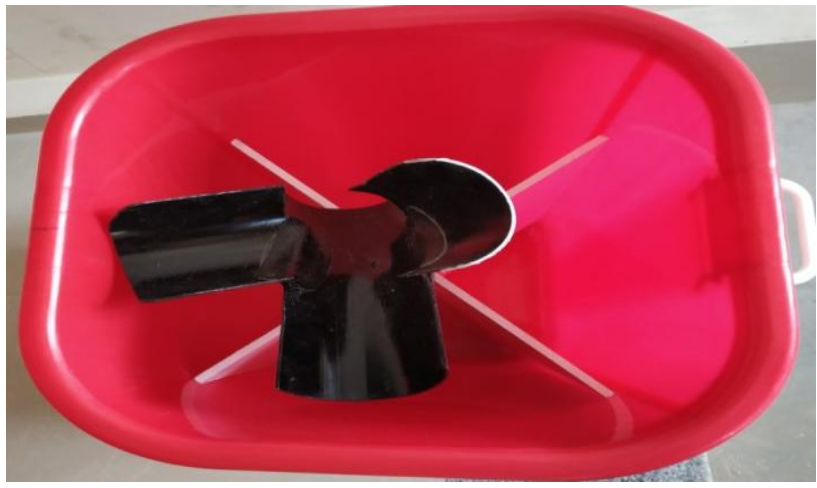

Fig. 5. Wing Attached to the Bin

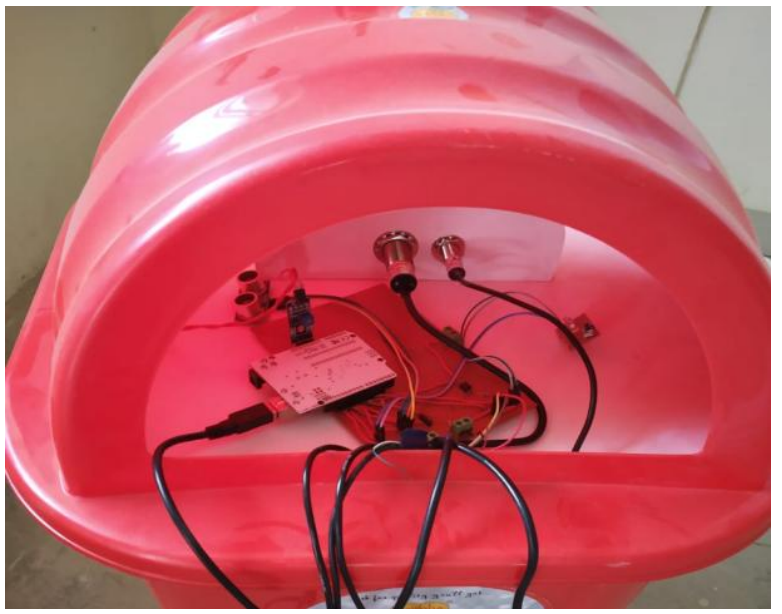

Fig. 6. Implementation of kit to make a smart dustbin

\section{SOFTWARE}

\section{A. Arduino IDE}

Arduino Integrated Development Environment is a software used to write and upload the code in languages such as $\mathrm{C}, \mathrm{C}++$, Java etc. The code written to perform a particular task is been uploaded into the respective microcontroller board with the help of this software. It displays the analog output of the system through a serial monitor. Arduino is a open source platform to build many electronics projects. It is the main component of this project which controls and co-ordinates all the sensors, motor and wing action.[2]

\section{RESULT ANALYSIS}

Waste segregation identifies where improvements / changes should be made to improve overall efficiency. As landfill and raw materials are running out it is vital that new techniques and methods are developed especially in segregation of waste. [5]

The usage of this project for waste segregation will lead to an increased efficiency in the department of waste management. Disposal of waste becomes much more easier. A major part of the waste is being reused or recycled by this project. An advanced version of this design can be used widely even in industries for segregating the waste produced. Segregation of waste becomes much more easier at the households and in other areas. This design will lead to the development of smart cities in India by improving the cleanliness of the country.[8]

Advancement of this project will increase the efficiency of waste disposal in our country. Segregation of waste on a daily basis becomes much more easier. This encourages the people to concentrate on waste segregation.[6]

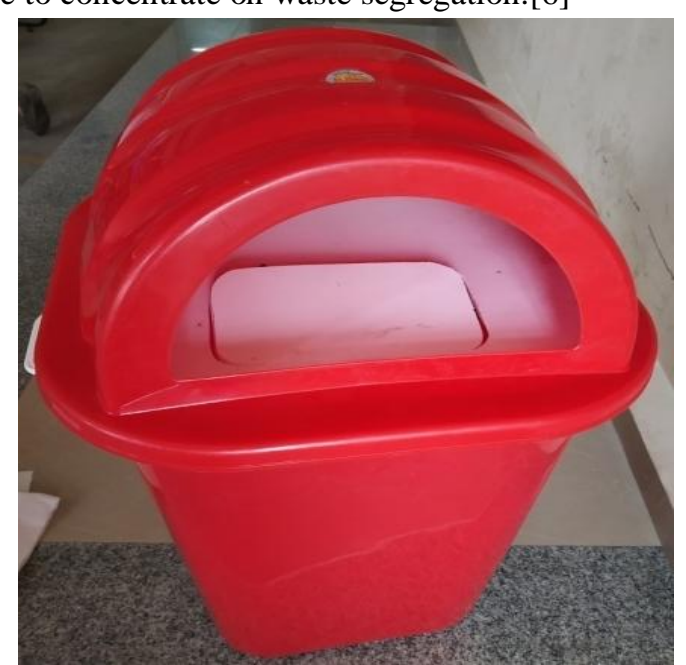

Fig. 7. Final setup

\section{CONCLUSION}

Waste segregation is a burning issue and there is ample potential in future development for various aspects of this research project. The bin designed by us can segregate only three types of waste. Advancement can be done to segregate all the types of waste available. These waste segregators should be available in all the places and should be available for the people all the time. Cost and portability aspects can be taken up for further development through research which would enable its use for an advanced purpose. Places with similar waste segregation issues can adopt the model developed without fundamental changes in the design. The simplicity and affordability of the model enables it to be designed and fabricated locally. Further research can be carried out on components of the model which enhances its flexibility of use in different waste scenarios.

The waste segregator designed also has potential for future research in being developed into a total mechanized system. Total mechanization would be an extension of the design aspects and incorporating more automation devices into the existing system. 
The model can be further developed into a totally automatic system where more resources are available and objectives are different.

\section{REFERENCES}

1. Ashwini D. Awale, Akshada A. Margaje, Akshay B. Jagdale "Automated waste segregator". Department of E \&TC Engineering,Shree Chhatrapati Shivajiraje College of Engineering Dhangawadi, Pune, India.

2. Balagugan, Raja S, Maheswaran T, Savitha S.'Implementation of Automated Waste segregator at household level", II Year P.G. Student, ME Embedded System Technologies, Sri Shakthi Institute of Engineering and Technology, Coimbatore, Tamilnadu, India

3. 1S.J. Ojolo, J.I. Orisaleye, Adelaja, A.O., Kilanko, O," Design and Development of waste sorting machine", Mechanical Engineering epartment, Lagos State University, Epe Campus, Lagos, Nigeria Covenant University, Ota. Nigeria

4. Stephen Kwasi Adzimah and Simons Anthony," Design of Garbage Sorting Machine",Department of Mechanical Engineering, Faculty of Engineering, University of Mines and Technology, Tarkwa, Ghana

5. R. Nicole, "Title of paper with only first word capitalized," J. Name Stand. Abbrev., in press.

6. Subhasini Dwivedi Michael Fernandes RohitD'souza ," A Review on PLC based Automatic waste segregator",

7. Gaurav Pawar, Abhishek Pisal, Ganesh Jakhad, Godson Koithodathu," Raspberry PI based automated waste segregation system",Student, Dept. of Electronics \& Telecommunication, MGM's Polytechnic, Aurangabad Maharashtra, India

8. Mahmudul Hasan Russel, Mehdi Hasan Chowdhury, Md ShekhNaim Uddin,AshifNewaz, Md. Mehdi MasudTalukder," Development of Automatic smart waste sorter machine", Department of Electrical and Electronics Engineering, Department of Mechanical Engineering Chittagong University of Engineering and Technology (CUET) Chittagong-4349, Bangladesh 